\title{
Does Surgical Approach Affect Patient-reported Function After Primary THA?
}

\author{
Sara C. Graves MD, MS, Benjamin M. Dropkin MD, Benjamin J. Keeney PhD, \\ Jon D. Lurie MD, MS, Ivan M. Tomek MD
}

Received: 23 July 2015/Accepted: 13 November 2015/Published online: 30 November 2015

(C) The Association of Bone and Joint Surgeons \& 2015

\begin{abstract}
Background Total hip arthroplasty (THA) relieves pain and improves physical function in patients with hip osteoarthritis, but requires a year or more for full postoperative recovery. Proponents of intermuscular surgical approaches believe that the direct-anterior approach may
\end{abstract}

The institution of two of the authors (BJK, JDL) has received, during the study period, funding from the National Institute for Arthritis and Musculoskeletal and Skin Diseases (NIAMS).

One of the authors certifies that he (BJK), has or may receive payments or benefits, during the study period, an amount of USD 10,000 to USD 100,000 from Berkley Medical Management Solutions (Greensboro, NC, USA). One of the authors certifies that he (JDL) has or may receive payments or benefits, during the study period, an amount of USD 10,000 to USD 100,000 from FzioMed (San Luis Obispo, CA, USA).

All ICMJE Conflict of Interest Forms for authors and Clinical Orthopaedics and Related Research ${ }^{\mathbb{R}}$ editors and board members are on file with the publication and can be viewed on request.

Each author certifies that his or her institution approved the human protocol for this investigation, that all investigations were conducted in conformity with ethical principles of research, and that informed consent for participation in the study was obtained.

This work was performed at Dartmouth-Hitchcock Medical Center, Lebanon, NH, USA.

\section{S. C. Graves}

Department of Orthopaedics and Sports Medicine, Central

Vermont Medical Center, Berlin, VT, USA

\section{B. M. Dropkin}

Department of Urologic Surgery, Vanderbilt University Medical Center, Nashville, TN, USA

\section{B. J. Keeney $(\bowtie)$}

Department of Orthopaedics, Geisel School of Medicine,

Dartmouth College, Dartmouth-Hitchcock Medical Center,

1 Medical Center Drive, Lebanon, NH 03756-0001, USA

e-mail: Benjamin.J.Keeney@Dartmouth.edu restore physical function more quickly than transgluteal approaches, perhaps because of diminished muscle trauma. To evaluate this, we compared patient-reported physical function and other outcome metrics during the first year after surgery between groups of patients who underwent primary THA either through the direct-anterior approach or posterior approach.

Questions/purposes We asked: (1) Is a primary THA using a direct-anterior approach associated with better patient-reported physical function at early postoperative times ( 1 and 3 months) compared with a THA performed through the posterior approach? (2) Is the direct-anterior approach THA associated with shorter operative times and higher rates of noninstitutional discharge than a posterior approach THA?

Methods Between October 2008 and February 2010, an arthroplasty fellowship-trained surgeon performed 135 THAs. All 135 were performed using the posterior approach. During that period, we used this approach when patients had any moderate to severe degenerative joint disease of the hip attributable to any type of arthritis refractory to nonoperative treatment measures. Of the patients who were treated with this approach, $21(17 \% ; 23$

\author{
J. D. Lurie \\ Departments of Medicine, Orthopaedics, and The Dartmouth \\ Institute for Health Care Policy \& Clinical Practice, Geisel \\ School of Medicine, Dartmouth College, Dartmouth-Hitchcock \\ Medical Center, Lebanon, NH, USA \\ I. M. Tomek \\ Department of Orthopaedics, Alice Peck Day Memorial Hospital, \\ Lebanon, NH, USA
}


hips) were lost to followup, whereas 109 (83\%; 112 hips) were available for followup at 1 year. Between February and September 2011, the same surgeon performed 86 THAs. All 86 were performed using the direct-anterior approach. During that period, we used this approach when patients with all types of moderate to severe degenerative joint disease had nonoperative treatment measures fail. Of the patients who were treated with this approach, 35 (41\%; 35 hips) were lost to followup, whereas 51 (59\%; 51 hips) were available for followup at 1 year. THAs during the surgeon's direct-anterior approach learning period (February 2010 through January 2011) were excluded because both approaches were being used selectively depending on patient characteristics. Clinical outcomes included operative blood loss; allogeneic transfusion; adverse events; patient-reported Veterans RAND-12 Physical (PCS) and Mental Component Summary (MCS) scores, and University of California Los Angeles (UCLA) activity scores at 1 month, 3 months, and 1 year after surgery. Resource utilization outcomes included operative time, length of stay, and discharge disposition (home versus institution). Outcomes were compared using logistic and linear regression techniques.

Results After controlling for relevant confounding variables including age, sex, and BMI, the direct-anterior approach was associated with worse adjusted MCS changes 1 and 3 months after surgery (1-month score change, -9 ; $95 \%$ CI, -13 to -5 ; standard error, 2), compared with the posterior approach (3-month score change, -9 ; 95\% CI, -14 to -3 ; standard error, 3 ) (both $\mathrm{p}<0.001$ ), while the direct-anterior approach was associated with greater PCS improvement at 3 months compared with the posterior approach (score change, 6; 95\% CI, 2-10; standard error, 2; $\mathrm{p}=0.008$ ). There were no differences in adjusted PCS at either 1 month or 12 months, and no clinically important differences in UCLA scores. Although the PCS score differences are greater than the minimum clinically important difference of 5 points for this endpoint, the clinical importance of such a small effect is questionable. At 1 year after THA, there were no intergroup differences in self-reported physical function, although both groups had significant loss-to-followup at that time. Operative time (skin incision to skin closure) between the two groups did not differ (81 versus 79 minutes; $p=0.411)$. Mean surgical blood loss (403 versus $293 \mathrm{~mL} ; \mathrm{p}<0.001$; adjusted, 119 more $\mathrm{mL}$; 95\% CI, 79-160; $\mathrm{p}<0.001)$ and in-hospital transfusion rates (direct-anterior approach, 20\% [17/86] versus posterior approach, $10 \%$ [14/135], $\mathrm{p}=0.050$; adjusted odds ratio, $3.6 ; 95 \% \mathrm{CI}, 1.3-10.1 ; \mathrm{p}=0.016)$ were higher in the directanterior approach group. With the numbers available, there was no difference in the frequency of adverse events between groups when comparing intraoperative complications, perioperative Technical Expert Panel complications, and other non-Technical Expert Panel complications within 1 year of surgery, although this study was not adequately powered to detect differences in rare adverse events.

Conclusions With suitable experience, the direct-anterior approach can be performed with expected results similar to those of the posterior approach. There may be transient and small benefits to the direct-anterior approach, including improved physical function at 3 months after surgery. However, the greater operative blood loss and greater likelihood of blood transfusions, even when the surgeon is experienced, may be a disadvantage. Given some of the kinds of bias present that we found, including loss to followup, the conclusions we present should be considered preliminary, but it appears that any benefits that accrue to the patients who had the direct-anterior approach would be transient and modest. Prospective randomized studies on the topic are needed to address the differences between surgical approaches more definitively.

Level of Evidence Level III, therapeutic study.

\section{Introduction}

Total hip arthroplasty (THP) is cost-effective and results in improvements in patients' quality of life [4, 21, 24]. There is a rapid pace of new implant designs, surgical techniques, and perioperative care improvements $[9,22]$. One unresolved area that is of interest is the surgical approach selected to perform the procedure. Two currently popular surgical approaches, the posterior approach with enhanced capsular closure (posterior approach) and direct-anterior Hueter approach (direct-anterior approach) have not been the subject of many comparative investigations, to our knowledge [12]. In addition, Higgins et al. [12] reported few studies used validated patient-reported outcome scores to compare how the two approaches affect early postoperative function and quality of life.

The posterior approach is the familiar modification of the Gibson-Moore [8, 14, 35] approach. Although posterior approaches historically have been associated with higher dislocation rates [17, 23, 27], these appear to be improved with enhanced closure techniques [5, 15, 17, 23]. The direct-anterior Hueter approach [32] is a modification of the traditional Smith-Petersen approach [18, 44] in the interval between the rectus femoris and tensor fascia lata muscles and often uses a specialized table to allow for intraoperative anterior exposure and positioning of the hip $[28,29]$. Numerous authors have reported low dislocation rates and rapid early functional recovery $[1,29,31,33,36$, 40, 46] with this approach. However, some studies have shown higher surgical blood loss and complication rates [6, 47], particularly for less-experienced surgeons [16, 43] or for patients who are obese [39]. Additionally, the distal 
extension of the approach is less familiar to most surgeons and a recent anatomic study by Grob et al. [10] suggested that it may pose a risk to the neurovascular supply to portions of the vastus lateralis. Other authors, however, have described techniques for safely extending the approach [20].

Although more studies are emerging as the direct-anterior approach gains popularity among surgeons, the number of prospective studies comparing the anterior and posterior approaches are not numerous $[2,6,31-34,38,46,50]$. Previous outcomes of interest have included length of stay, walking distance, hip-specific function measures, surgery time, blood loss, complications, and dislocations [2, 3135]. However, there are no data contrasting the differences in patient-reported physical function between the two approaches. The principal question of this single-surgeon (IMT) comparative study was to determine whether improvement in postoperative patient-reported physical function was associated with surgical approach after adjustment for patient baseline characteristics and other factors.

We therefore asked: (1) Is primary THA using a directanterior approach associated with better patient-reported physical function at early postoperative times ( 1 and 3 months) compared with THA performed through the posterior approach? (2) Is a direct-anterior approach THA associated with shorter operative time and higher rates of noninstitutional discharge than a posterior approach THA?

\section{Materials and Methods}

\section{Study Design and Setting}

To better answer the question of which approach resulted in better patient function and activity levels, we used the following validated instruments: Veterans Rand-12 (VR12) item questionnaire for physical (PCS) and mental component scores (MCS) and the University of California, Los Angeles (UCLA) activity score. We used a before-andafter study design with prospectively collected patient-reported outcome data as the primary clinical outcome measure. Between October 2008 and February 2010, a fellowship-trained arthroplasty surgeon (IMT), with 7 years of practice as an attending orthopaedic surgeon at the start of the study period and 9 by the completion of the period, performed 135 THAs. All 135 were performed using the posterior approach. During that period, we used this approach when patients had any moderate to severe degenerative joint disease of the hip attributable to any type of arthritis refractory to nonoperative treatment measures. Of the patients who were treated with this approach, $21(17 \%$; 23 hips) were lost to followup, while 109 (83\%;
112 hips) were available for followup at 1 year. Between February and September 2011, the surgeon performed 86 THAs. All 86 were performed using the direct-anterior approach. During that period, we used this approach when patients with all types of moderate to severe degenerative joint disease had nonoperative treatment measures that failed. Of the patients who were treated with this approach, 35 (41\%; 35 hips) were lost to followup, whereas 51 (59\%; 51 hips) were available for followup at 1 year. Procedures performed between February 25, 2010, and January 31, 2011 were excluded owing to the learning period for the direct-anterior approach. During the learning curve, the direct anterior THAs took markedly longer to complete. The first 10 cases had surgical times in excess of 2 hours, after which the next 10 took between 90 to 120 minutes. In terms of adverse events, there were two femoral perforations with the femoral broach. Because the perforations occurred relatively proximally (adjacent to the lesser trochanter), a standard femoral stem was used to bypass the fracture. In addition, there was one greater trochanter fracture. Because the fracture involved only the tip of the greater trochanter and the trochanteric attachment of the glutei was not compromised, no formal repair was done. No additional information was obtained on the transition THAs.

Patients were identified through a search of institutional claims data by Current Procedural Terminology code for primary THA (27130) performed by the operating surgeon (IMT) during the periods of interest and crosschecked against a spreadsheet of all primary THAs obtained from an institutional review board-approved research database. The medical records of all patients identified by this search also were reviewed manually. Patients were excluded if they had bilateral simultaneous THAs or if they had concurrent procedures (such as removal of previous hardware or arthroscopy). Patients for whom information was missing for outcomes variables were excluded from the relevant analyses only (Fig. 1). There were no additional exclusion or inclusion criteria.

A posterior approach with enhanced capsular closure technique was performed in a manner similar to that described by Pellicci et al. [35], with posterior capsular repair to bone through drill holes. The direct-anterior approach technique was similar to that described by Matta et al. [29], with excision versus repair of a small portion of the anterosuperior capsule. All procedures had resident participation commensurate to their level of training and skill under the direct supervision of the attending surgeon. Anesthesia type was determined by discussion between anesthesia staff and respecting the preferences of the patient. Specific data were not collected regarding anesthesia type, although we acknowledge this as an important variable that should be included in future investigations. 


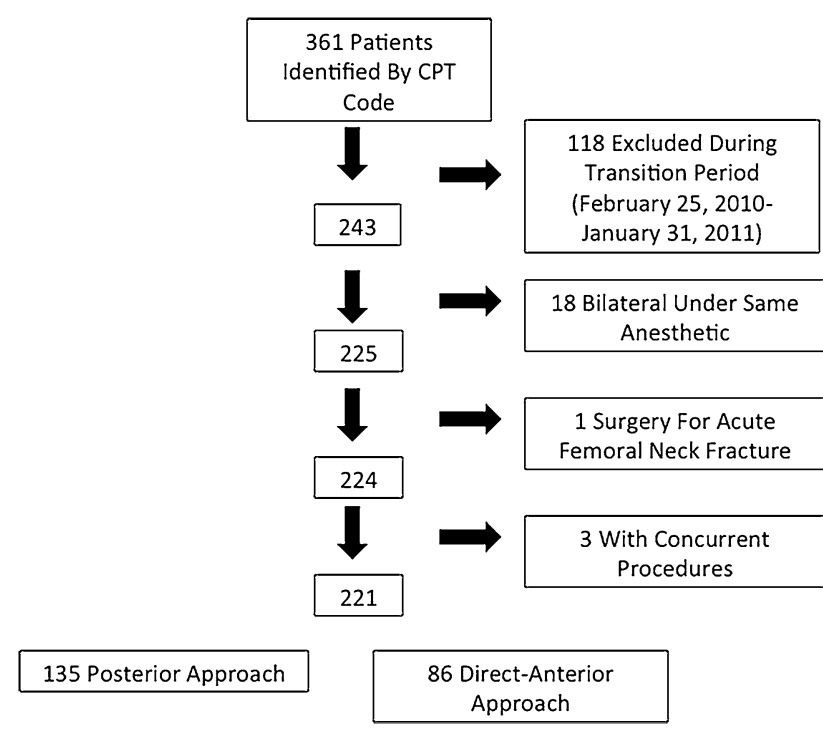

Fig. 1 The patient inclusion and attrition rates are shown for patients who had THAs with the posterior approach and those who had the direct-anterior approach. CPT $=$ Current Procedural Terminology.

Intraoperative fluoroscopy was used for all patients undergoing a direct-anterior approach THA only and for none of the patients who had a posterior approach THA.

Patients followed a standardized postoperative pathway with order sets and mobilization with physical therapy and nursing staff on postoperative Day 0 or 1 , depending on their immediate postoperative recovery and medical status. All patients received postoperative antibiotics for a 24-hour period (cefazolin [1-3 g intravenously based on patient weight] unless allergic, in which case vancomycin $[1 \mathrm{~g}$ intravenously] or clindamycin [600 mg or $900 \mathrm{mg}$ intravenously based on weight] was used). Antithrombotic agent selection was based on risk stratification performed preoperatively (warfarin, enoxaparin, or aspirin, with all patients having sequential compression devices [Covidien, Kendall, MA, USA], compression stockings, and early ambulation). All patients were allowed full weightbearing as tolerated postoperatively and patients undergoing the posterior approach were asked to adhere to posterior hip dislocation precautions. All patients were allowed full weightbearing to tolerance, usually with a walker or crutches. Some patients elected to go directly to use of a cane. These precautions entailed no adduction past midline, no internal rotation past neutral, and no hip flexion past $90^{\circ}$ for 1 month after surgery. There were no precautions for patients undergoing the direct-anterior approach. Care coordinators were engaged for all patients to determine their needs at discharge, with consideration of physical therapy recommendations.

The arthroplasty pathway at the study institution was constant during the study period with the posterior dislocation precautions in patients undergoing a posterior approach THA as the only differentiator between the patients having the direct-anterior approach and those having the posterior approach. All patients were asked to return to the clinic for followup at routine approximate intervals of 4 weeks, 3 months, and 1 year. Patients were encouraged to participate in outpatient physical therapy at their 4-week followup.

The electronic medical record (Epic Systems Corporation, Verona, WI, USA) was reviewed and data entered in a secure electronic research electronic data capture (REDCap) [11] database. All patient-reported survey data were entered prospectively at each clinic visit through an electronic patient portal as a matter of routine care in our institution. Patient-reported outcome surveys, operative notes, perioperative anesthesia records, inpatient notes, discharge summaries, and office notes were reviewed for all patients by research staff. All Technical Expert Panel and other relevant complications were recorded. No outcomes data beyond 13 months postoperatively were analyzed to maintain consistency between the comparison groups. The principal means of avoiding bias in the two patient cohorts was by including all consecutive patients in the before (posterior approach) and after (direct-anterior approach) cohorts of the study and not selecting the approach based on patient characteristics.

\section{Study Outcomes}

We used the VR-12 as our principle outcome of interest. The VR-12 is an extensively used nonproprietary patient questionnaire developed from the SF-36 that quantifies patient limitations attributable to physical and emotional problems. The PCS and MCS are on a scale from 0 to 100 with higher scores indicating better health or function, normalized to adult Americans for a score of 50 and a standard deviation of 10 [19, 42]. Following previous work, we considered a change of 5 points to be the minimum clinically important difference for the PCS and MCS [45]. The UCLA activity score is scored from 1 to 10 , with lower scores representing less activity and more reliance on others and higher scores representing participation in impact sports. The minimally clinically important difference for this has been defined as 0.9 [45]. Other secondary outcomes included estimated surgical blood loss, which was estimated from blood in the suction canister and from saturation of surgical sponges, by the surgeon in discussion with anesthesia providers, and need for transfusion during hospitalization. Although our study was underpowered to detect differences in rare adverse events, this information was collected from chart review. 


\section{Statistical Analysis}

Using Stata ${ }^{\circledR}$ 12C and 12MP (StataCorp LP, College Station, TX, USA) statistical software, baseline demographic characteristics of the cohort were identified and assessed for differences between the two groups using means and one-way ANOVA for continuous variables and chi-square analysis for categorical variables.

Linear and logistic regression models were constructed adjusting for the following baseline characteristics: age, gender, tobacco use, BMI, race, THA laterality, presence or absence of cement, employment status, and American Society of Anesthesiologists score. Each patient's mean change from baseline to each time was used as the outcome of interest for each patient-reported outcome measure: physical function and mental function.

A power analysis indicated that we had $80 \%$ power to detect a 4-point difference in baseline VR-12 scores between groups. As a result of loss of followup and resulting lower patient counts, we could detect only a 6-point difference (power $=0.823$ ) for 1-year postsurgery comparisons.

There was a higher frequency of cement use and metalon-metal bearing surfaces in the posterior approach group (Table 1). Metal-on-metal bearings were absent in the direct-anterior approach THA group, given increasing awareness of the problems with this bearing surface during the period of the direct-anterior approach surgery [30]. Because metal-on-metal bearings were present in only one of the groups, this factor could not be adjusted for in the model. However, the analysis was run with and without patients with metal-on-metal implants, and there was no effect on the results or our conclusions (data not shown).
One additional finding in the study populations was that the preoperative PCS scores were somewhat higher for the patients who had the direct-anterior approach and their MCS scores were lower at baseline $(p<0.05)$. Because we used a consecutive series of patients and there was no difference in the way referrals were processed by our clinic, this finding represented a change in the patient-reported functional status of the patients who underwent THA during the study period and could represent more active patient self-selection bias toward a surgeon performing the direct-anterior approach.

Significant numbers of patients were lost to followup by 1 year, which is a limitation of the study (Figs. 1 and 2). Among patients seen for 1-year followup, not all completed survey information. Even when patients are greeted in the waiting room and asked to fill out surveys on tablets, it can be challenging for them to complete the surveys for numerous reasons, despite strong institutional and provider support.

Of the 135 patients in the posterior approach group, 128 had baseline PCS and were included in this analysis; of these, followup VR-12 PCS were available for $76 \%$ at 1 month, $66 \%$ at 3 months, and $45 \%$ at 1 year. For patients in the directanterior approach group, 84 of 86 had baseline VR-12 scores with $100 \%, 83 \%$, and $43 \%$ supplying followup scores at 1 month, 3 months, and 1 year, respectively.

\section{Results}

Primary THA using a direct-anterior approach was associated with minimal changes to patient-reported physical function at early postoperative times compared with the

Table 1. Patient characteristics at baseline

\begin{tabular}{|c|c|c|c|}
\hline Characteristic & $\begin{array}{l}\text { Posterior approach } \\
(\mathrm{n}=135)\end{array}$ & $\begin{array}{l}\text { Direct -anterior approach } \\
(\mathrm{n}=86)\end{array}$ & $\mathrm{p}$ value \\
\hline Sex (female, \%) & 61 & 57 & 0.506 \\
\hline Age (mean, years) & 61 & 61 & 0.781 \\
\hline BMI (mean, $\mathrm{kg} / \mathrm{m}^{2}$ ) & 30 & 28 & 0.057 \\
\hline Laterality (left hip, \%) & 45 & 45 & 0.981 \\
\hline Primary diagnosis of osteoarthritis (\%) & 83 & 83 & 0.938 \\
\hline Cemented femoral stem (cement use,) & 13 & 0 & $<0.001$ \\
\hline ASA score $(3-6$ versus $0-2, \%)$ & 30 & 25 & 0.387 \\
\hline Tobacco (currently using, \%) & 13 & 5 & 0.036 \\
\hline Race (other than white, \%) & 5 & 2 & 0.297 \\
\hline Work status (self-identifying as disabled, \%) & 16 & 8 & 0.072 \\
\hline Metal-on-metal bearings ( $\%$ implanted) & 14 & 0 & $<0.001$ \\
\hline Preoperative mean UCLA [35] score & 4.4 & 4.9 & 0.104 \\
\hline Preoperative mean physical component score $[17,18]$ & 29 & 35 & $<0.001$ \\
\hline Preoperative mean mental component score $[17,18]$ & 52 & 40 & $<0.001$ \\
\hline
\end{tabular}

Probability values obtained through chi-square analysis for categorical variables and one-way ANOVA for continuous variables; UCLA = University of California Los Angeles; ASA = American Society of Anesthesiologists. 
Fig. 2 Survey counts of patient-reported University of California Los Angeles (UCLA) activity scores and Veteran's RAND 12 (VR-12) Physical Component Scores are shown for posterior and direct-anterior approaches during the preoperative and postoperative periods.

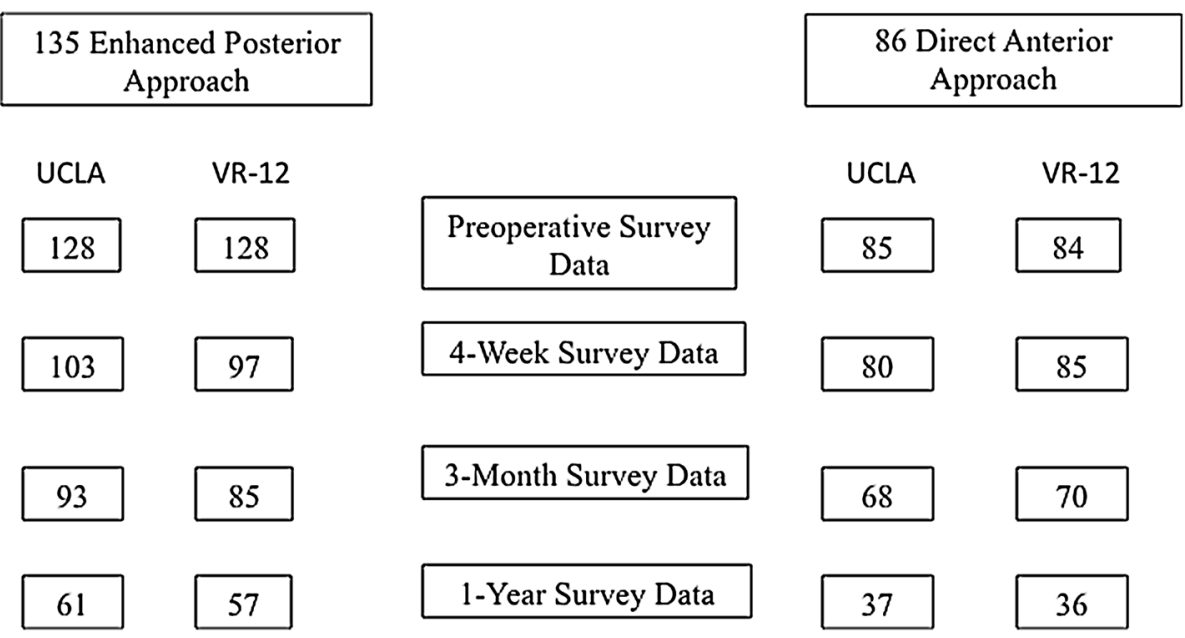

posterior approach (Table 2). After adjustment, there was no significant difference in 1-month PCS (direct-anterior approach showed 4.0 more points improvement; $95 \% \mathrm{CI}$, -0.1 to $8.0 ; \mathrm{p}=0.055)$. There was improvement after adjustment in UCLA activity score [49] at 1 month for the direct-anterior group compared with posterior approach group (0.7 point improvement; $95 \%$ CI, $0.02-1.3 ; \mathrm{p}=$ 0.042), although it did not meet the minimum clinically important difference of 0.9 [45] (Fig. 3). The 3-month PCS score for direct-anterior approach THAs did result in statistically and clinically greater improvement change score relative to posterior THA (6 points more improvement; 95\% CI, 2-10; p = 0.008) (Fig. 4). However, this improvement is only 1 point higher than the minimum clinically important difference of 5 points [45]. There was no difference between approaches in any 1-year outcome analyses. There also were no differences in operative times or rates of noninstitutional discharge between patients having the different THA approaches.

Secondary outcomes of the study included VR-12 MCS, blood loss, rates of transfusion, and Technical Expert Panel complication rates (Table 2). The MCS for patients who had the direct-anterior approach showed negative changes compared with scores for the posterior approach at 1 and 3months postoperatively, but showed positive change at 1 year (1-month score difference, $-9 ; 95 \% \mathrm{CI},-13$ to $-5 ; \mathrm{p}$ $<0.001$ ); (3-month score difference, -9 ; $95 \% \mathrm{CI},-14$ to $-3 ; \mathrm{p}=0.004) ;(1-$ year score difference, $13 ; 95 \%$ CI, 7-19; $\mathrm{p}<0.001$ ) (Fig. 5). After adjustment, there was greater blood loss (119 more $\mathrm{mL}$; 95\% CI, 79-160; $\mathrm{p}<0.001)$ and higher odds of transfusion (adjusted odds ratio, 3.6; 95\% CI, $1.3-10.1 ; \mathrm{p}=0.016)$ in the direct-anterior group. This study was not adequately powered to detect a difference in TEP complication rates and did not find a difference (Table 3).

\section{Discussion}

Finding ways to further facilitate patient recovery from primary total hip replacement, such as refining surgical approach, may be beneficial to patients eager to resume activities of leisure and employment. In this before-andafter study, we found that early improvement in patientreported physical function between the direct-anterior and posterior THA approaches favored the direct-anterior approach, even though the difference was modest and noted only at the 3-month interval. Additionally, a slight difference in transfusion rates favoring the posterior approach was seen, even after adjustment for patient characteristics.

There were some notable limitations of our study. One of the most important considerations in the adoption of any new surgical approach is what the learning curve is for the procedure, and we opted to exclude patients who had surgery during this time from the study to see what the differences were between the approaches after sufficient experience. However, others [16, 47] have found higher rates of complications with this approach during the early period of use, with complications including fracture, lateral femoral cutaneous nerve palsy, and much higher blood loss $[6,39,47]$. The surgeon (IMT) at our institution was an arthroplasty fellowship-trained surgeon with 7 to 8 years of experience at the start of the study, therefore his learning curve may have been shorter with less complications than for lower-volume surgeons with less arthroplasty experience. Additionally, he gained several years of experience during the course of the study that could have contributed to the improved early results and shorter length of stay in the direct-anterior group. Woolson et al. [47] described more frequent early complications with the direct-anterior approach in a community setting. Our results reflect the 


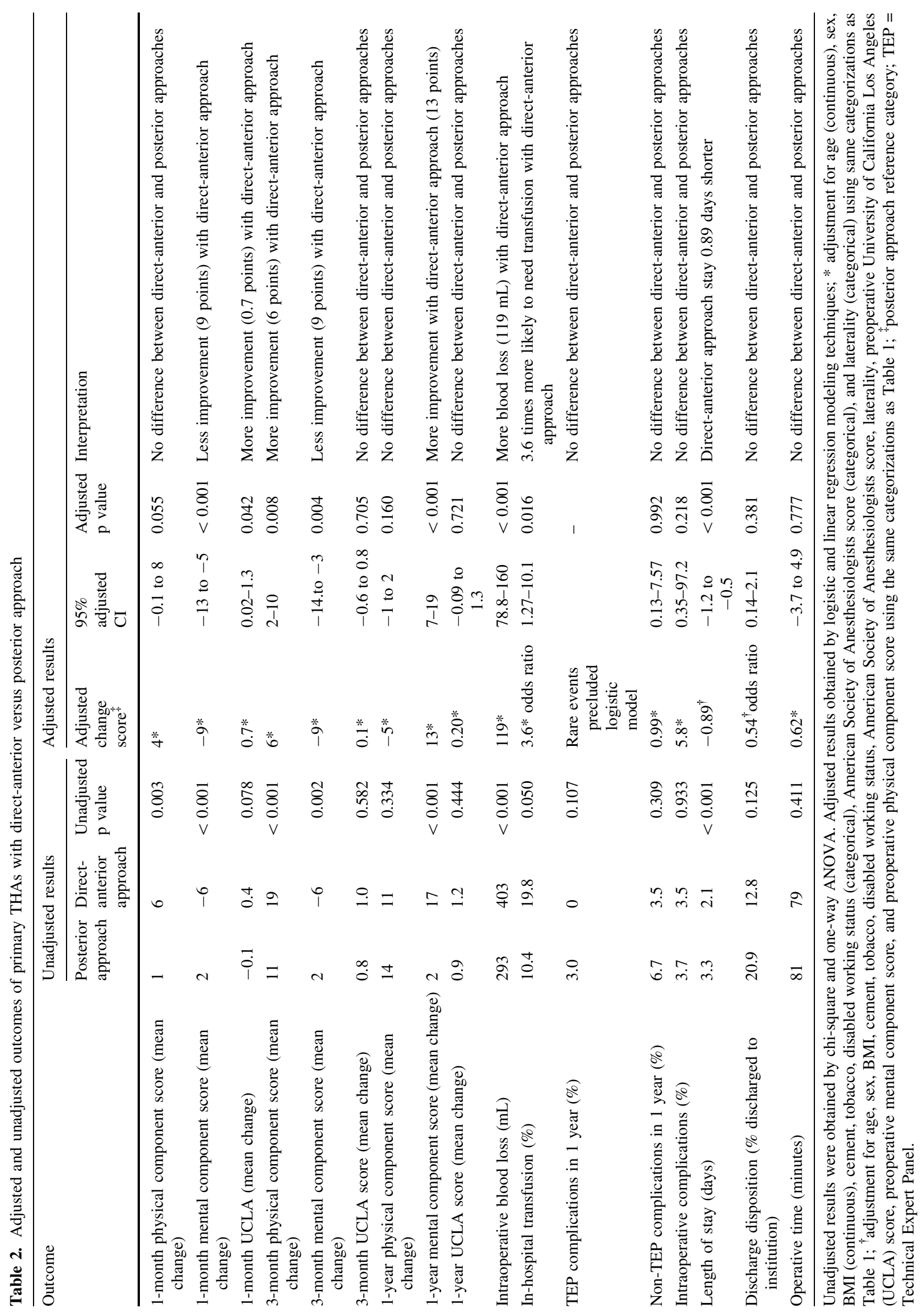




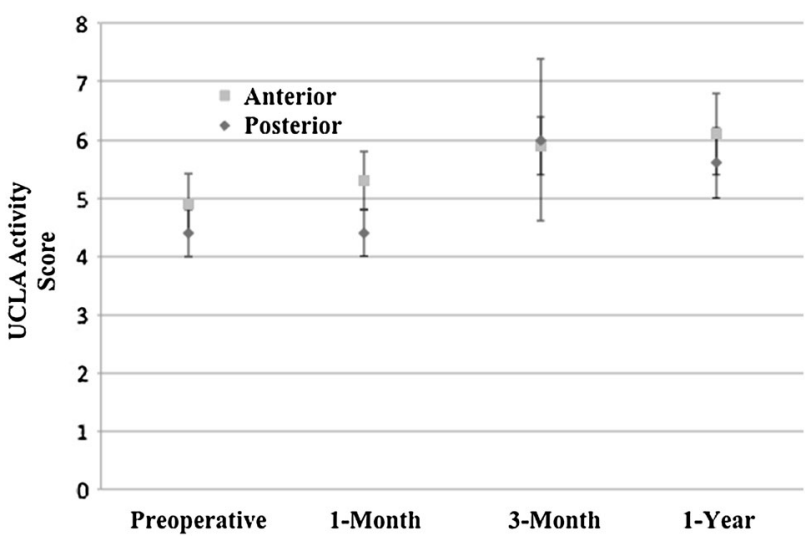

Fig. 3 University of California Los Angeles (UCLA) activity scores preoperatively, at 1-month, 3-month, and 1-year followups are shown. The $95 \%$ CIS are denoted for each group.

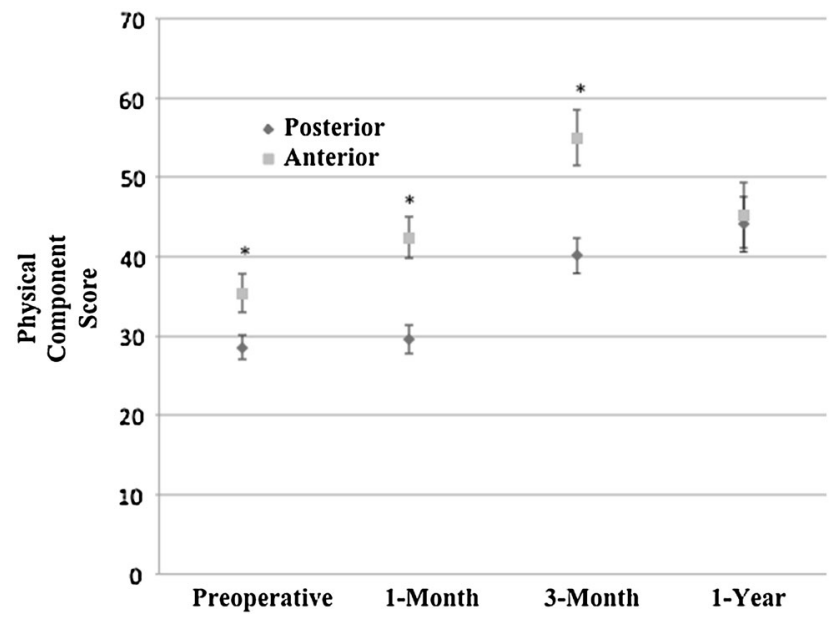

Fig. 4 Physical component scores (Veteran's Rand-12) preoperatively, at 1-month, 3-month, and 1-year followups are shown. Ninetyfive percent CIs are shown and significantly different results $(p<$ 0.05 ) are designated with an asterisk.

surgeon's experience as a high-volume, fellowship-trained, academic surgeon (IMT) experienced with both approaches; the results of other surgeons or practices may be different. Unlike other studies, we noted no difference in length of surgery between the two approaches; we surmise this could be attributable to the surgeon's volume and prestudy experience; the surgeon is one of the faster surgeons on our institution staff (data not shown) and therefore these specific findings are not surprising. Although the primary surgeon, practice, and institution characteristics were consistent between our cohort groups, it may be speculated that there were temporal trends at the institution or in medical care, which may affect the results. Additionally, the operating surgeon (IMT) was one of two surgeons at the institution who performed the direct-anterior approach THAs during this time, and the only one to offer direct-anterior approach THAs for patients regardless

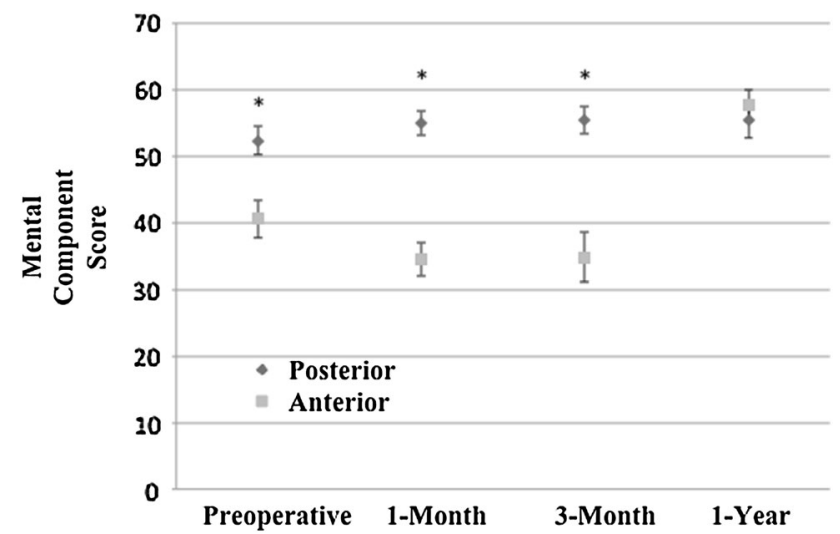

Fig. 5 Mental component scores (Veteran's Rand-12) preoperatively, at 1-month, 3-month, and 1-year followups are shown. Ninety-five percent CIs are shown and significantly different results $(p<0.05)$ are designated with an asterisk.

of weight, body habitus, and surgical complexity. As a result patients may have self-selected for the direct-anterior approach by asking to see this surgeon instead of his colleagues, which may explain the preoperative differences between the approach cohorts. However, we did adjust for these differences using robust statistical methods. Another significant limitation concerns the lower response rates for postoperative patient-reported outcomes, particularly at 1 year. Patient-reported outcomes are difficult to obtain postoperatively, as noted in several publications [7, 41, 45]. After data collection for our study ended, we achieved great improvements in capturing patient-reported outcomes across all times of orthopaedic care (data not shown). These changes fall outside the scope of the current study. Other limitations of the study included the observational nature of this investigation and possible omitted variable bias, despite our attempts to account for adjusting variables. Without blinding and with the difference in postoperative hip precaution instructions, patient and provider expectations may have confounded the physical function improvements seen. Our results also are affected by relatively low and differential followup between groups, with $83 \%$ of patients available for followup at 1 year in the posterior group and 59\% in the direct-anterior group. It is possible there were characteristics of the patients who were lost to followup that could affect our results. However, there were no observed differences between patients with and without 1-year PCS followup data, including for mean age ([60.9 years; SD, 11.7 years; 95\% CI, 58.5-63.3 years] vs [61.2 years; SD, 13.0 years; $95 \% \mathrm{CI}, 59.0-63.5$ years] $\mathrm{p}$ $=0.833)$, gender ([66\% female, 63 of 96$]$ vs $[55 \%, 69$ of 125], $\mathrm{p}=0.117$ ), and mean BMI ([29.0; SD, 7.6; 95\% CI, 27.4-30.5] vs [29.0; SD, 6.6; 95\% CI, 27.8-30.2], $\mathrm{p}=$ 0.994). The strength of our study is that the patient cohort represented a consecutive series, a so-called "before-and- 
Table 3. Additional details regarding complications grouped by surgical approach

\begin{tabular}{|c|c|c|}
\hline Complication type & Posterior approach THA & Direct-anterior approach THA \\
\hline Intraoperative & $\begin{array}{l}2 \text { calcar fractures requiring cerclage } \\
2 \text { acetabular fractures } \\
1 \text { trochanteric fracture }\end{array}$ & $\begin{array}{l}1 \text { calcar fracture } \\
1 \text { greater trochanteric avulsion fracture } \\
1 \text { broken screwdriver requiring additional } \\
\text { intraoperative time }\end{array}$ \\
\hline Postoperative & $\begin{array}{l}1 \text { atrial fibrillation } \\
2 \text { demand ischemia } \\
1 \text { dislocations } \\
1 \text { hearing loss } \\
1 \text { postoperative hematoma } \\
1 \text { posterior capsular failure requiring repair } \\
1 \text { supraventricular tachycardia requiring cardioversion }\end{array}$ & $\begin{array}{l}1 \text { femoral nerve stretch injury } \\
1 \text { intensive care unit admission for hypoxia } \\
1 \text { lateral femoral cutaneous nerve palsy }\end{array}$ \\
\hline $\begin{array}{l}\text { Technical Expert } \\
\text { Panel }\end{array}$ & $\begin{array}{l}1 \text { readmission within } 30 \text { days (pancreatitis) } \\
1 \text { death (cardiac failure) } \\
1 \text { return to operating room within } 30 \text { days (fall and wound } \\
\text { dehiscence) } \\
1 \text { respiratory failure }\end{array}$ & None meeting criteria \\
\hline
\end{tabular}

after" study design. As a result, the surgeon was not selecting patients for one approach versus the other; the approach used was dependent on the calendar rather than on patient characteristics. This may have mitigated selection bias to an extent, since we compared periods where the surgeon performed only posterior approach THAs with a time where he performed only direct-anterior THAs.

There was a slightly greater improvement in the 1month UCLA activity score in the direct-anterior group at 1 month that did meet the minimum clinically important difference threshold; however, there was no difference in 1-month PCS. At 3 months, there was slightly greater clinical improvement in PCS. However, these functional improvements did not persist at 1 year, and the minimally clinically important differences for these measures must be considered in the interpretation of the results. In a study of specific physical tasks after THA, Barrett et al. [2] found that patients undergoing a direct-anterior approach THA had improved stair-climbing and walking ability at 6 weeks postoperatively. Others also found improved mobility during the early points with the direct-anterior approach [3, $19,26,47]$ but no apparent long-term advantage at 1 year $[2,25]$. One additional finding of our study was the greater adjusted improvement from baseline among patients undergoing the posterior approach in their early postoperative MCS scores compared with scores of patients who had the direct-anterior approach. Taunton et al. [46] briefly mentioned this in their study of the early posterior approach. By 1 year after THA, however, our patients undergoing direct-anterior approach THAs had greater improvements in their MCS scores than patients undergoing the posterior approach. Speculatively, it may be that the anticipation and public enthusiasm surrounding the directanterior approach during this approximate period may have generated unrealistic expectations for rapid return to activities that were not met. Our results may reflect the best outcomes of an experienced expert academic surgeon, performed using both approaches with learning periods, in a real-world, pragmatic observational setting.

There was an association with higher intraoperative blood loss and transfusion use in the direct-anterior approach group. Barrett et al. [2] also found higher blood loss with the direct-anterior approach. Higher blood loss can lead to postoperative anemia, which, if severe, can lead to increased incidence of cardiac, renal, and cerebrovascular events [34]. Allogeneic transfusions are not without risks, including infectious disease transmission, transfusion reaction, and immune modulation as possible consequences [37]. No such events were noted in our study patients. Our study was performed during a time when we were not routinely using tranexamic acid to diminish intraoperative bleeding rates $[13,48]$, and this would be a good topic for future investigations.

Despite our limitations, we conclude that with suitable experience, the direct-anterior approach can be performed with an expectation of long-term results similar to those achievable with the posterior approach. There may be transient and small benefits to regaining physical function with the direct-anterior approach, but future studies should examine these questions with a more rigorous study protocol. Studies with randomized cohorts and more complete survey data followup after surgery are needed to minimize such baseline differences between cohorts. Finally, the study results may not be generalizable to other 
surgeons without arthroplasty training and other institutions, particularly nonacademic or lower-volume surgeons or institutions.

Acknowledgments The operating surgeon (IMT) conveys his appreciation and thanks to Joel Matta MD (Hip \& Pelvis Institute, Santa Monica, CA, USA) and Stefan Kreuzer MD (Department of Orthopedic Surgery, University of Texas Medical School at Houston, Houston, TX, USA) for allowing him to observe the direct-anterior approach THA in their operating rooms.

\section{References}

1. Bal BS, Vallurupalli S. Minimally invasive total hip arthroplasty with the anterior approach. Indian J Orthop. 2008;42:301-308.

2. Barrett WP, Turner SE, Leopold JP. Prospective randomized study of direct anterior vs postero-lateral approach for total hip arthroplasty. J Arthroplasty. 2013;28:1634-1638.

3. Bergin PF, Doppelt JD, Kephart CJ, Benke MT, Graeter JH, Holmes AS, Haleem-Smith H, Tuan RS, Unger AS. Comparison of minimally invasive direct anterior versus posterior total hip arthroplasty based on inflammation and muscle damage markers. J Bone Joint Surg Am. 2011;93:1392-1398.

4. Chang RW, Pellisier JM, Hazen GB. A cost-effectiveness analysis of total hip arthroplasty for osteoarthritis of the hip. JAMA. 1996;275:858-865.

5. Chiu FY, Chen CM, Chung TY, Lo WH, Chen TH. The effect of posterior capsulorrhaphy in primary total hip arthroplasty: a prospective randomized study. J Arthroplasty. 2000;15:194-199.

6. Christensen CP, Karthikeyan T, Jacobs CA. Greater prevalence of wound complications requiring reoperation with direct anterior approach total hip arthroplasty. J Arthroplasty. 2014;29:18391841.

7. Franklin PD, Harrold L, Ayers DC. Incorporating patient-reported outcomes in total joint arthroplasty registries: challenges and opportunities. Clin Orthop Relat Res. 2013;471: 3482-3488.

8. Gibson A. Posterior exposure of the hip joint. J Bone Joint Surg Br. 1950;32:183-186.

9. Gomez PF, Morcuende JA. Early attempts at hip arthroplasty: 1700s to 1950s. Iowa Orthop J. 2005;25:25-29.

10. Grob K, Monahan R, Gilbey H, Ackland T, Kuster MS. Limitations of the vastus lateralis muscle as a substitute for lost abductor muscle function: an anatomical study. J Arthroplasty. 2015. doi:10.1016/j.arth.2015.06.047.

11. Harris PA, Taylor R, Thielke R, Payne J, Gonzalez N, Conde JG. Research electronic data capture (REDCap): a metadata-driven methodology and workflow process for providing translational research informatics support. J Biomed Inform. 2009;42:377-381.

12. Higgins BT, Barlow DR, Heagerty NE, Lin TJ. Anterior vs. posterior approach for total hip arthroplasty, a systematic review and meta-analysis. J Arthroplasty. 2015; 30: 419-434.

13. Ho KM, Ismail $\mathrm{H}$. Use of intravenous tranexamic acid to reduce allogeneic blood transfusion in total hip and knee arthroplasty: a meta-analysis. Anaesth Intensive Care. 2003;31:529-537.

14. Hunter SC. Southern hip exposure. Orthopedics. 1986;9:14251428.

15. Iorio R, Specht LM, Healy WL, Tilzey JF, Presutti AH. The effect of EPSTR and minimal incision surgery on dislocation after THA. Clin Orthop Relat Res. 2006;447:39-42.

16. Jewett BA, Collis DK. High complication rate with anterior total hip arthroplasties on a fracture table. Clin Orthop Relat Res. 2011;469:503-507.
17. Jolles BM, Bogoch ER. Posterior versus lateral surgical approach for total hip arthroplasty in adults with osteoarthritis. Cochrane Database Syst Rev. 2006;3:CD003828.

18. Judet J, Judet H. [Anterior approach in total hip arthroplasty] [in French]. Presse Med. 1985;14:1031-1033.

19. Kazis LE, Selim A, Rogers W, Ren XS, Lee A, Miller DR. Dissemination of methods and results from the veterans health study: final comments and implications for future monitoring strategies within and outside the veterans healthcare system. $J$ Ambul Care Manage. 2006;29:310-319.

20. Kennon R, Keggi J, Zatorski LE, Keggi KJ. Anterior approach for total hip arthroplasty: beyond the minimally invasive technique. $J$ Bone Joint Surg Am. 2004;86(suppl 2):91-97.

21. Kozma CM, Slaton T, Paris A, Edgell ET. Cost and utilization of healthcare services for hip and knee replacement. J Med Econ. 2013;16:888-896.

22. Kurtz SM, Ong KL, Lau E, Widmer M, Maravic M, GomezBarrena E, Mde F, Manno V, Torre M, Walter WL, de Steiger R, Geesink RG, Peltola M, Roder C. International survey of primary and revision total knee replacement. Int Orthop. 2011;35:17831789 .

23. Kwon MS, Kuskowski M, Mulhall KJ, Macaulay W, Brown TE, Saleh KJ. Does surgical approach affect total hip arthroplasty dislocation rates? Clin Orthop Relat Res. 2006;447:34-38.

24. Lavernia CJ, Alcerro JC. Quality of life and cost-effectiveness 1 year after total hip arthroplasty. J Arthroplasty. 2011;26:705709 .

25. Maffiuletti NA, Impellizzeri FM, Widler K, Bizzini M, Kain MS, Munzinger U, Leunig M. Spatiotemporal parameters of gait after total hip replacement: anterior versus posterior approach. Orthop Clin North Am. 2009;40:407-415.

26. Martin CT, Pugely AJ, Gao Y, Clark CR. A comparison of hospital length of stay and short-term morbidity between the anterior and the posterior approaches to total hip arthroplasty. $J$ Arthroplasty. 2013;28:849-854.

27. Masonis JL, Bourne RB. Surgical approach, abductor function, and total hip arthroplasty dislocation. Clin Orthop Relat Res. 2002;405:46-53.

28. Matta JM, Ferguson TA. The anterior approach for hip replacement. Orthopedics. 2005;28:927-928.

29. Matta JM, Shahrdar C, Ferguson T. Single-incision anterior approach for total hip arthroplasty on an orthopaedic table. Clin Orthop Relat Res. 2005;441:115-124.

30. Milosev I, Trebse R, Kovac S, Cor A, Pisot V. Survivorship and retrieval analysis of Sikomet metal-on-metal total hip replacements at a mean of seven years. J Bone Joint Surg Am. 2006;88:1173-1182.

31. Mirza AJ, Lombardi AV Jr, Morris MJ, Berend KR. A minianterior approach to the hip for total joint replacement: optimising results: improving hip joint replacement outcomes. Bone Joint J. 2014;96(11 suppl A):32-35.

32. O'Brien RM. The technic for insertion of femoral head prosthesis by the straight anterior or Hueter approach. Clin Orthop. 1955;6:22-26.

33. Oinuma K, Eingartner C, Saito Y, Shiratsuchi H. Total hip arthroplasty by a minimally invasive, direct anterior approach. Oper Orthop Traumatol. 2007;19:310-326.

34. Partridge J, Harari D, Gossage J, Dhesi J. Anaemia in the older surgical patient: a review of prevalence, causes, implications and management. J R Soc Med. 2013;106:269-277.

35. Pellicci PM, Bostrom M, Poss R. Posterior approach to total hip replacement using enhanced posterior soft tissue repair. Clin Orthop Relat Res. 1998;355:224-228.

36. Rachbauer F. [Minimally invasive total hip arthroplasty via direct anterior approach] [in German]. Orthopade. 2005;34:1103-1104, 1106-1108, 1110. 
37. Raghavan M, Marik PE. Anemia, allogenic blood transfusion, and immunomodulation in the critically ill. Chest. 2005;127:295307.

38. Rathod PA, Orishimo KF, Kremenic IJ, Deshmukh AJ, Rodriguez JA. Similar improvement in gait parameters following direct anterior \& posterior approach total hip arthroplasty. J Arthroplasty. 2014;29:1261-1264.

39. Russo MW, Macdonell JR, Paulus MC, Keller JM, Zawadsky MW. Increased complications in obese patients undergoing direct anterior total hip arthroplasty. J Arthroplasty. 2015;30:1384-1387.

40. Sariali E, Leonard P, Mamoudy P. Dislocation after total hip arthroplasty using Hueter anterior approach. J Arthroplasty. 2008;23:266-272.

41. Schamber EM, Takemoto SK, Chenok KE, Bozic KJ. Barriers to completion of patient reported outcome measures. J Arthroplasty. 2013;28:1449-1453.

42. Selim AJ, Rogers W, Fleishman JA, Qian SX, Fincke BG, Rothendler JA, Kazis LE. Updated U.S. population standard for the Veterans RAND 12-item Health Survey (VR-12). Qual Life Res. 2009;18:43-52.

43. Seng BE, Berend KR, Ajluni AF, Lombardi AV Jr. Anteriorsupine minimally invasive total hip arthroplasty: defining the learning curve. Orthop Clin North Am. 2009;40:343-350.
44. Smith-Petersen MN. Evolution of mould arthroplasty of the hip joint. J Bone Joint Surg Br. 1948;30:59-75.

45. SooHoo NF, Li Z, Chenok KE, Bozic KJ. Responsiveness of patient reported outcome measures in total joint arthroplasty patients. J Arthroplasty. 2015;30: 176-191.

46. Taunton MJ, Mason JB, Odum SM, Springer BD. Direct anterior total hip arthroplasty yields more rapid voluntary cessation of all walking aids: a prospective, randomized clinical trial. J Arthroplasty. 2014;29(9 suppl):169-172.

47. Woolson ST, Pouliot MA, Huddleston JI. Primary total hip arthroplasty using an anterior approach and a fracture table: short-term results from a community hospital. J Arthroplasty. 2009;24:999-1005.

48. Yamasaki S, Masuhara K, Fuji T. Tranexamic acid reduces postoperative blood loss in cementless total hip arthroplasty. $J$ Bone Joint Surg Am. 2005;87:766-770.

49. Zahiri CA, Schmalzried TP, Szuszczewicz ES, Amstutz HC. Assessing activity in joint replacement patients. J Arthroplasty. 1998;13:890-895.

50. Zawadsky MW, Paulus MC, Murray PJ, Johansen MA. Early outcome comparison between the direct anterior approach and the mini-incision posterior approach for primary total hip arthroplasty: 150 consecutive cases. J Arthroplasty. 2014;29:1256-1260. 